\title{
The Problem of Patent Thickets in Convergent Technologies
}

\author{
GAVIN CLARKSON AND DAVID DEKORTE \\ University of Michigan, Ann Arbor, Michigan 48109-1107, USA
}

\begin{abstract}
Patent thickets are unintentionally dense webs of overlapping intellectual property rights owned by different companies that can retard progress. This article begins with a review of existing research on patent thickets, focusing in particular on the problem of patent thickets in nanotechnology, or nanothickets. After presenting visual evidence of the presence of nanothickets using a network analytic technique, it discusses potential organizational responses to patent thickets. It then reviews the existing research on patent pools and discusses pool formation in the shadow of antitrust enforcement. Based on recent research on patent pool formation, it examines the divergent fate of two recent pools and discusses the prospects for the future formation of nanotechnology patent pools, or nanopools.
\end{abstract}

KEYWORDS: nanotechnology; patents; intellectual property

\section{INTRODUCTION}

Nanotechnology is poised to be the first major technological revolution of the 21st century, yet there is a growing concern that future innovation and commercialization will be inhibited by the explosive rate of nanotechnology patenting and the potential for the formation of patent thickets. These dense webs of overlapping intellectual property rights owned by different companies (Shapiro 2000) can present a significant barrier that must be hacked through in order to commercialize new technology. In other industries characterized by cumulative innovations and multiple blocking patents, the existence of such densely concentrated patent rights can have the perverse effect of stifling innovation rather than encouraging it. Such patent thickets are already problematic in other convergent technology areas such as biotechnology (Heller and Eisenberg 1998; Clark et al. 2000; Horn 2003) and information technology (Clarkson 2004).

Address for correspondence: Gavin Clarkson, Assistant Professor, University of Michigan, School of Information, School of Law, Native American Studies, 304 West Hall, 1085 S. University Ave., Ann Arbor, MI 48109-1107. Voice: 734-763-2284; fax: 734-764-2475.

e-mail: gsmc@umich.edu

Ann. N.Y. Acad. Sci. 1093: 180-200 (2006). (C) 2006 New York Academy of Sciences. doi: 10.1196/annals.1382.014 
Progress in the field of nanotechnology has been rapid over the past half century, with laboratories in corporations and universities researching the ability to successfully create working objects at this level. From 1985 until 2005, there were 3818 nanotech patents issued in the United States, with an additional 1777 outstanding patent applications published since 2001 (Lux 2005). This number is expected to increase exponentially as the processes required to create such technologies are further developed over the next several decades.

Nanotechnology is a quickly growing area, and has the possibility for revolutionizing a vast array of different fields and industries, including health care, electronics, pharmaceuticals, and others. According to Lux Research (2003) study, public and private companies spent $\$ 3$ billion worldwide on nanotechnology. This spending only shows signs of increasing over the next several years. Given this level of spending, developing a strategy to deal with the problem of nanothickets is critical, not only to the researchers developing these new technologies but also the corporations and institutions that fund them. Without appropriate strategies, firms will be unable to capitalize on their investments, and researchers may be prevented from conducting even the most basic research because nanothickets constitute such a potentially imposing obstacle.

While nanotechnology as a scientific domain has a number of unique attributes that render it particularly susceptible to the development of patent thickets, the problem of patent thickets is not new. Over the last century and a half, organizations in technology industries attempting to advance their innovative activities have often stumbled into patent thickets (Clarkson 2004). Although the organizational responses varied widely, certain organizations have occasionally responded by constructing patent pools or organizational structures where multiple firms collectively aggregate patent rights into a package for licensing, either among themselves or to any potential licensees irrespective of membership in the pool. Such collaboration among technologically competing firms, however, has often encountered difficulty from an antitrust standpoint, even if the formation of the pool is procompetitive.

\section{THE PROBLEM OF NANOTHICKETS}

A patent does not guarantee the right to make or do anything. Instead, a patent gives the patent owner the right to exclude others from making, using, or selling anything that embodies the technology covered by the patent. When a given organization has all of the necessary patents to develop a given technology, it can proceed without intellectual property entanglements. When multiple organizations each own individual patents that are collectively necessary for a particular technology, however, their competing intellectual property rights form a "patent thicket" (Clarkson 2005).

The problem of patent thickets has recently caught the attention of much of the scientific and engineering community in a number of technological 
arenas (Heller and Eisenberg 1998; Merges 1999; Clark et al. 2000; Newberg 2000; Shapiro 2000; FTC 2002, 2003; Gilbert 2002; Glover 2002; Horn 2003; Lerner et al. 2003; Clarkson 2004, 2005). For example, firms in the semiconductor industry "find it all too easy to unintentionally infringe on a patent in designing a microprocessor, potentially exposing themselves to billions of dollars of liability and/or an injunction forcing them to cease production" (Shapiro 2000, p. 121). Heller and Eisenberg (1998) lament the "anticommons" in biomedical research due to the problem of patent thicketing. Particularly in the biopharmaceutical industry, patent thickets threaten the process of cumulative innovation because they act "as barriers to entry [that prevent new entrants] from using the technologies protected by such patent thickets" (Glover 2002, p. C10).

A recent FTC (2003) report notes that in certain industries the large number of issued patents makes it virtually impossible to search all the potentially relevant patents, review the claims contained in each of those patents, and evaluate the infringement risk or the need for a license. For the software industry the report cites testimony about the hold-up problems and points out "that the owner of any one of the multitude of patented technologies constituting a software program can hold up production of innovative new software" (2003, ch. 2, p. 3 ). For many firms, the only practical response to this problem of unintentional and sometimes unavoidable patent infringement is to file hundreds of patents each year to have something to trade during cross-licensing negotiations. In other words, the only rational response to the large number of patents in a given field may be to contribute to it.

The nanotechnology patent space experiences an even greater level of these problems because it is much more complicated than other technology areas. Because nanotechnology by definition encompasses a broad class of systems and materials, searching for nanotechnology-related publications and patents can be difficult, relative to other fields (Bawa 2004). Part of the complexity relates to the fact that nanotechnology spans a wide variety of already established fields. Because nanotechnology can be used in biomedical applications, the patent for a particular innovation may fall into the realm of biomedical patents. Likewise, a patent may be related to other such fields and classified in those fields. The present global patent classification systems are not sufficiently descriptive or designed to allow for the many unique properties that are inherent in nanotechnology innovations.

One study found that approximately 3700 patents issued between 2001 and 2003 contained one or more of several nanotechnology-related terms (Sampat 2004). These patents span 200 different US patent classes and were examined by 794 unique primary patent examiners; this last number is approximately one-quarter of the patent examiners employed by the United States Patent and Trademark Office (PTO) over this time period. As a result, a diverse group of examiners from a wide variety of backgrounds examined nanotechnology patent applications rather than examiners who could focus on nanotechnology attributes. 
In order to address concerns stemming from the influx of new applications based on nanotech, the PTO announced in October 2004 that it had created a new classification for nanotechnology, Classification 977. This new classification defines nanotechnology very narrowly, however. According to the PTO, Class 977 provides for disclosures that are "(i) related to research and technology development at the atomic, molecular or macromolecular levels, in the length of scale of approximately 1-100 nanometer range in at least one dimension; and (ii) that provides a fundamental understanding of phenomena and materials at the nanoscale and to create and use structures, devices, and systems that have novel properties and functions because of their small and/or intermediate size." 1

The creation of this new patent class did not solve the examiner problem identified by Sampat (2005), however, as a 2005 study of Class 977 by ETC Group notes that over 290 different primary patent examiners were assigned to evaluate the various Class 977 patents. This incredibly large number of examiners raises the concern that overlapping and conflicting patents could have been issued by different examiners at about the same time, with no knowledge of other such events occurring. The problem with granting such patents is obvious: if two companies with overlapping or conflicting patents unknowingly go to market with products based on these patents, it is likely that neither would have a claim superseding the other, leading to negative economic consequences to both firms. As such, the granting of those patents is in neither company's interest.

One patent examiner noted that while the creation of Class 977 is a noteworthy step, "it should be viewed as a starting point in a much larger effort to ensure that patent law develops smoothly with regard to nanotechnology." (Mouttet 2005, p. 260). Because many of the search terms used in the study by Sampat do not actually use the term "nanotechnology," it is very possible that those patents would be wholly assigned to different classifications where overlapping may occur. For example, patent thickets of overlapping patents may already be in place, given that a patent claiming a carbon nanotube would potentially conflict with similar patent applications claiming either carbonaceous cylinders or elongated cylinders. Although the recent formation of patent class 977 for Nanotechnology coupled with training for examiners in nanotechnology terminology and concepts may ameliorate the patent thicketing problem somewhat, ultimately innovators will still be forced to hack their way through these ever-burgeoning patent thickets. Because of these issues, the opportunity for collaboration and discussion between examiners on nanotechnology concerns is limited compared to other fields for which the PTO has instituted primary classification.

Related to the difficulties with classification of nanotechnology patents are the obstacles faced when searching the vast database of patents, a necessary step in both applying for patents as well as in prosecuting them. Due to the sheer

1 Available at http://www.PTO.gov/go/classification/uspc977/defs977.htm 
volume of material necessary to search through when conducting searches in the patent landscape, the utilization of automated techniques are necessary in order to comb through the variety of patents that have been filed. Zucker and Darby (2005) discussed one such way that nanotechnology research could be captured via NanoBank, although this proposal is more focused on the problem of overlapping research than on overlapping patents. As a result, this technique and other automated techniques are not effective when searching for "prior art" claims in nanotechnology due to the lack of a unified classification scheme for nanotech (Bawa 2004).

Another concern with the secondary nature of classifying nanotechnology in a patent application involves the possibility for applicants to author their applications so that specific nanotech terminology is omitted. Such omissions may be justified in order to prevent competitors from having access to key parts of the innovation with the expectation that the competitors would not be able to gain access to the knowledge that led to the invention.

A further problem with the new classification as a secondary classification leads directly to other problems with protections and prosecutions. The nanotech field lacks a standard terminology with which to describe the inventions in the nanotechnology sphere, leading to important difficulties in patenting these inventions (Molenda 2004). In many fields and industries, both technical and common terms are used in certain ways specific to that field in order to advance the understanding of various concepts in that field or industry. Because nanotechnology is such a relatively new field, the unique terminology has neither been established nor standardized; as a result, it may be difficult for applicants, examiners, and courts to understand the specific meanings behind the terminology used to describe these patents.

In his article on the importance of defining terminology in the nanotechnology field, Molenda (2004) discusses various notable cases in which such terminology was vital to the decision. In one court case addressing the question of terminology, the Court of Appeals for the Federal Circuit (CAFC) ${ }^{2}$ stated that the terms in a patent claim "bear a 'heavy presumption' that they mean what they say and have the ordinary meaning that would be attributed to those words by persons skilled in the relevant art." ${ }^{3}$ Importantly, the CAFC indicated that it should derive the "ordinary meaning" of claim terms from dictionaries, encyclopedias, and treatises. ${ }^{4}$

As Molenda points out, however, while the court should look to such reference sources to ascertain the meanings of the various terms used in patent applications, the definitions of the terms can vary widely. One such difference is illustrated by the variations in the definition of the word "crystal." Whereas Webster's II New Riverside Dictionary gives a relatively simple definition of

2 The CAFC has exclusive jurisdiction over appeals involving patents.

3 Texas Digital Systems, Inc. vs. Telegenix, Inc., 308 F. 3d 1193, 1202 (2002).

4308 F.3d at 1202-03. 
the term, the McGraw-Hill Encyclopedia of Science and Technology, published the year after the Webster edition, provides a much more technical definition of the term. ${ }^{5}$ The interpretation of this term would depend greatly upon which definition the court found to carry more weight within the scope of the particular patent in question. As a result, the lack of standardized technology within the field of nanotechnology could produce an element of uncertainty in patent prosecution that would not exist otherwise.

This difficulty is mitigated should the patent applicant define the terminology within the application itself. In one case involving an applicant who had included a lexicon of terminology within the application, the court looked to this lexicon in reaching an understanding of the terms in question. ${ }^{6}$ As a result, applicants interested in the legal implications of a particular application should seek to define the terms employed in the application as clearly as possible to ensure that these terms are not misconstrued by either the patent court or competitors looking to appropriate the technology, thus avoiding unnecessary economic harm resulting from an unsuccessful patent prosecution.

The Constitutional mandate under which the PTO operates was designed to encourage innovation by inventors by providing short-term protection so that the inventor may develop the product in a reduced-competition environment. In return for this protection, the inventor agrees to make the application public so that others with interests related to the patent may improve upon the invention in the future. The field of nanotechnology is so dynamic that it presents distinctive problems. As Lemley (2005) discussed, the building blocks of so-called "enabling" technologies - computer software, hardware, the Internet, and biotechnology, among others - were left unpatented in earlier fields of invention. According to Darby and Zucker (2003), while patents are important for protecting particular biotechnology products, natural excludability provided important informal protection by slowing the dissemination of the requisite knowledge. Such is not the case in nanotechnology where firms and universities are looking to patent as much as possible as soon as possible (Lemley 2005).

\section{IDENTIFYING NANOTHICKETS}

So how has the rush to patent nanotechnology affected the patent landscape for nanotechnology? Although Clarkson's (2005) methodology for patent

5 Page 169 of Webster's II New Riverside (Rev. ed. 1996) defines "crystal" as "A 3-dimensional structure made up of atoms, molecules or ions arranged in basic units that are repeated throughout the structure." McGraw-Hill Encyclopedia of Science \& Technology 630 (8th edition 1997) defines "crystal" as "A solid in which the atoms or molecules are arranged periodically. .. In scientific nomenclature, the term crystal is usually short for single crystal, a single periodic arrangement of atoms. .. In electronics the term is usually restricted to mean a single crystal which is piezoelectric."(emphasis added).

63 Innovative Properties Co. vs. Avery Dennison Corp., 350 F.3d 1365 (Fed. Cir. 2003). 
thicket detection is not yet fully applicable because no nanotechnology patent pools exist to evaluate, such mechanisms for mapping the patent space and identifying patent network density can still be applied because the nanotechnology patents and citations are available.

Clarkson's measure is derived from the standard network analytic measure of density. Social Network Analysis is a methodology developed by sociologists and organizational theorists to examine the social structure of groups. In this type of analysis, individuals are identified as the actors in a network, and the relationships between those actors identified are identified as ties. If the relationship from actor A to actor B can be different from the relationship from actor B to actor A, the network is referred to as a directed network (or directed graph).

While social network analysis, as a science, has been most commonly applied to describe complex dynamics in human interaction, the underlying theory and methodology is not limited to interpersonal relationships. Network analysis describes the relationships among nodes, be they people, computers, power stations, academic papers, or patents. Existing network analytic research in other areas of information sciences has concentrated on patterns of citation in literature and research (Price 1965, 1976; Redner 1998), and Newman (2000, 2001) has written extensively on the analysis of coauthorship networks within academic communities and scholarly publishing. Patents share many similar characteristics - citation practices in particular - to academic works, and that research is quite relevant. Patent space as an information network bears significant similarity to academic citation networks based on temporal limitations that specifically affect the directionality of linking vectors within a network. Similar to academic papers, a new entrant can only give citation to previous research or "prior art." Because of this linear path, patents that give rise to increased innovation can be seen as significant in creating lineages or families of technologies - possibly the seeds from which a patent thicket grows (Freeman 1979).

Previous work has demonstrated the methodological validity of using network analysis on patents. In an early study of patent networks, Podolny and Stuart (1995) developed the concept of a "technological niche" that included a focal innovation, the innovations on which the focal innovations built, the innovations that built upon the focal innovation, and the technological ties among the innovations within the niche. Using patents as the network nodes and patent citations as the network ties between nodes, they then were able to measure characteristics of innovation niches within the semiconductor industry to determine how subsequent innovations may or may not build upon the focal innovation. Those same authors used similar techniques in two subsequent articles. One article examined the evolution of technological positions among firms (Stuart and Podolny 1996), and the other examined organizational survival within technological niches (Podolny et al. 1996).

Not only did these early studies establish the methodological validity of applying network analytic techniques to patent networks in general, but much 
TABLE 1. Nanoscale science and engineering keywords (Sampat 2004)

Atomistic simulation
Atomic force microscop*
Biomotor
Molecular device
Molecular electronics
Molecular modeling
Molecular motor
Molecular sensor
Molecular simulation
Nano*
Quantum computing
Quantum dot*
Quantum effect $*$
Scanning tunneling microscop*
Self assembl $*$
Self assembl $*$

of their analysis of technological niches and competitive crowding was also based on a variation of network density, a fundamental network analytic concept (Marsden 1990; Wasserman and Faust 1994). As part of a study of patent thickets in electronics and medical devices, Clarkson made certain necessary modifications for the temporal constraints of patent networks. He also developed a modified density calculation for the patent space in order to examine patent thickets and calculate patent thicket densities and was able to demonstrate that patent thickets are objectively differentiable from the surrounding patent universe (Clarkson 2005).

To visualize the growing patent thicket in nanotechnology, we began by downloading front-page data for all of the patents issued since 2000 from the PTO's ftp site. We then searched the patent abstracts using the terms listed in TABLE 1 and identified 2998 nanotechnology patents issued between January 1, 2000 and December 31, 2004. Using an automated XML parser, we were able to extract the intragroup citations for the downloaded nanotechnology patents. In order to visualize the growth of the patent thicket, we utilized some of the network analytic techniques have been applied to patent spaces for purposes of visualization. Force-directed placement techniques (Fruchterman and Reingold 1991) have been used to present arrangements identifying complex information spaces (Schroeder 1999), and Clarkson (2005) previously incorporated this technique into a network analytic computational methodology for mapping patent space and visually identifying patent thickets.

To represent the temporal nature of nanothicket growth, we generated a series of graphs for each year of our data set. FIGURE 1 illustrates the relationships between patents in the nanotechnology space for the years 2000, 2002, and 2004. Each point in the figure represents one patent, and the edges denote a reference made by one patent to another in the space. 
A report by Lux Research (2005) indicates that there may be multiple nanothickets, covering three separate platform technologies: dendrimers, quantum dots, and carbon nanotubes. According to their report, fullerenes and nanowires seem less crowded. Given the presence of ever increasing nanothickets covering at least three of five fundamental nanotechnology platforms, however, the logical next question would be what should firms do in response to the presence of nanothickets?

\section{PATENT POOLS}

Patent thickets are not a new phenomenon, and when the total number of owners of the conflicting intellectual property rights is small, the response to the patent thicket problem has often been to cross-license (Grindley and Teece 1997; Teece 1998, 2000). When more than two parties are involved, however, the transaction costs of cross-licensing between all of the parties can be prohibitive, and additional economic barriers exist such as hold-ups and double marginalization (Viscusi et al. 2000). In response to these challenges throughout the last 150 years, organizations have attempted to solve the multiparty patent thicketing problem by constructing patent pools. Usually, each firm assigns or licenses its individual intellectual property rights to a specific entity that in turn exploits the collective rights by licensing, manufacturing, or both. Different licensing arrangements are then available, depending on whether the licensee is a member of the pool and how the resulting royalties are subsequently distributed among the members of the pool.

While even the PTO has suggested patent pooling as a solution to the patent thicketing problem (Clark et al. 2000), the cooperative formation of patent pools by technologically competing firms has often encountered difficulty from an antitrust standpoint, even if the pool itself has procompetitive benefits. While the antitrust and intellectual property regimes were frequently in tension for most of the 20th century, with patent pooling often facing rather aggressive antitrust enforcement even in situations where the pool was procompetitive, recent developments indicate, however, that these two areas of law can be aligned so as to foster rather than stifle innovation. The 1995 Guidelines for the Licensing of Intellectual Property (IP Guidelines), jointly issued by the US Department of Justice (DOJ) and the Federal Trade Commission (FTC), formally acknowledged that collective ownership structures for intellectual assets, including patent pools, could potentially be procompetitive solutions to the patent thicket problem.

Although the revenues generated from sales of devices based in whole or in part on patent pool technologies are at least $\$ 100$ billion US per year (Clarkson 2004), the patent pooling phenomenon has received few scholarly treatments, and most of those have been historical in nature. Vaughan (1925) describes patent pool formation in the late 19th and early 20th century and examines a 

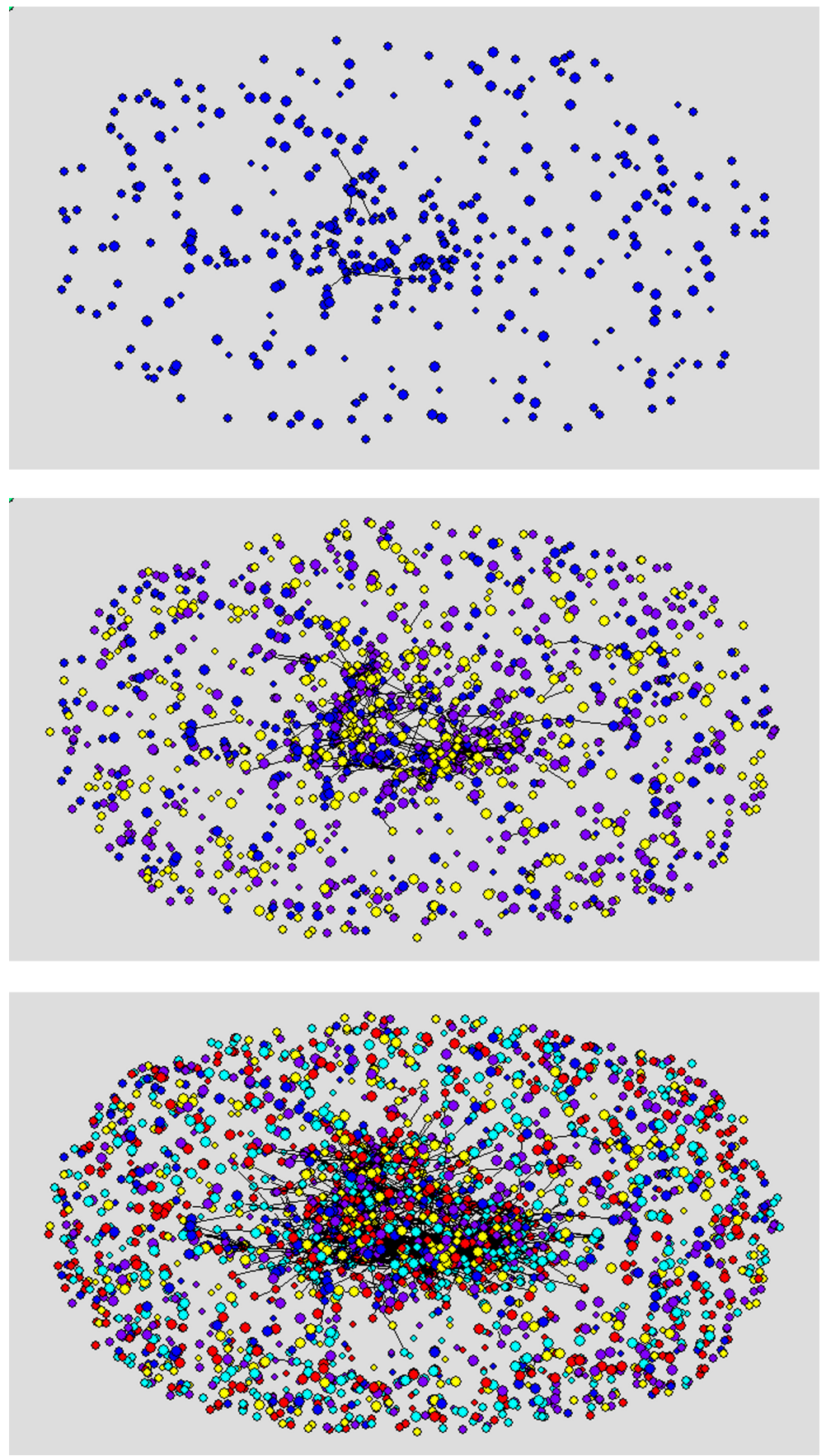

FIGURE 1. Growth of Nanotechnology Patents, 2000, 2002, 2004. 
number of early pools. Three examinations of the phenomenon have been in the form of case studies. Cassady (1959) examines the formation and operation of a patent pool by Thomas Edison that aggregated all of the important patents for the early motion picture industry. Thompson (1987) describes the first patent pool, which was formed in the 19th century around intellectual property conflicts in the sewing machine industry. Bittlingmayer (1988) examines the formation of an aircraft patent pool during World War I. While many scholars have written favorably about patent pool formation (Vaughan 1925; Merges 1996, 1999; Newberg 2000), others have focused on potential competitive problems posed by patent pools (Priest 1977; Taylor 1992; Carlson 1999).

A number of economists have recently written on patent pools. Both Choi (2003) and Shapiro (2003) have examined patent pools in the context of patent litigation settlements constrained by antitrust law. In a different article specifically examining patent pools, Shapiro (2000) uses Cournot's (1838) original analysis of the "complements problem" to argue that patent pools raise welfare when patents are perfect complements and harm welfare when they are perfect substitutes. Work by Lerner and Tirole (2004) extends the analysis by examining the strategic incentives to form a pool in the presence of current and future innovations that are either substitutes for or complements to the patents in the pool. Their model allows examination of the full range between the polar cases of perfectly substitutable and perfectly complementary patents. Their paper concludes that while much research remains to be done, the construction of procompetitive pools is certainly possible. Stable pools can be formed by clearly defining patent essentialness and by scrutinizing the economic incentives provided to patent holders through pool membership versus independent licensing.

Lerner and Tirole's (2004) second paper on patent pools empirically examines the positive aspects of these arrangements, developing a set of theoretical predictions concerning the pool structure. They predict how the attributes of the pool vary with their key characteristics, such as the number of members of the pool and the rate of technical advance in the industry. They sample 63 pools established between 1895 and 2001 from the dockets of court cases, the archives of congressional hearings, and many other sources, to determine the actual structure of the pooling agreements. Their study concludes that the dynamics of management become more centralized as the pool grows larger. As pool membership increases, third-party licensing becomes more common. Such a finding is significant because restrictions on third-party licensing have historically been a trigger for antitrust scrutiny.

Gilbert (2002) reviews the antitrust treatment of patent pooling over the same time period and examines the factors that the courts identified as pertinent to the antitrust outcome. He concludes that until recently, the competitive relationship of the patents was not a major determinant of the antitrust outcome in most cases. Instead, he suggests that the courts have focused on restrictive licensing terms that affect downstream prices, although 
he argues that the competitive relationships between the patents should be the most important factor in assessing the procompetitiveness of a given pool.

Following Lerner et al.'s archival approach, Clarkson (2004) studied 101 patent pools that were at one time accused of antitrust violations by either the Antitrust Division of the DOJ, the FTC, or private antitrust actions between 1900 and 1970. The analysis indicated that a primary determinant of pool survival was an examination by the court of the existence of an underlying patent thicket. Clarkson (2005), however, notes the problems associated with a general lack of capability on the part of the antitrust regime to make an objective determination of the existence of a patent thicket, and he proposes such an objective measure based on patent thicket density.

Recent history also demonstrates the problematic nature of the antitrust regime's inability to objectively verify the existence of a patent thicket. On June 26, 1997, the DOJ issued a Business Review letter indicating that a patent pool based on MPEG-2, a technology standard for compactly representing digital video and audio signals for consumer distribution, was deemed not to be in violation of the antitrust laws of the United States. Less than a year later, however, on March 24, 1998, the FTC filed a complaint against a patent pool formed around photorefractive keratectomy (PRK), or laser eye surgery technology, and ultimately forced the pool to dissolve. Although the two pools had a number of similar characteristics, the antitrust regime gave its blessing to the MPEG pool but destroyed the PRK pool. According to Newberg (2000), the FTC litigation involving the PRK patent pool either ignored or failed to detect the underlying laser eye surgery patent thicket and did not see that the PRK pool was actually a procompetitive solution to the underlying patent thicket.

\section{PATENT POOLS IN TWO CONVERGING TECHNOLOGIES}

If patent pools in nanotechnology are to be a possible solution to nanotechnology patent thickets, they must be able to survive antitrust scrutiny. It is therefore instructive to briefly examine the divergent fates of these two recent patent pools involving the two best-established areas currently converging with nanotechnology, namely information technology and biotechnology.

The MPEG pool involves technology for digitally coded representation of moving pictures, audio, and their combination in compressed formats. The MPEG working group responsible for developing the technology standard is part of the International Telecommunication Union (ITU). Standard-setting organizations like the ITU are cognizant of the potential problem of patent thickets and have developed policies designed to prevent patent thickets from thwarting the adoption of standards-based technologies. For example, the ITU's Patent Policy provides that the holder of any known patent or any pending patent application related to any proposal made to the ITU in the process of 
standards-setting must submit a written statement, either waiving those patent rights or committing to negotiate licenses for those rights on a nondiscriminatory basis and on reasonable terms and conditions. Such licensing provisions are often referred to as Reasonable and Nondiscriminatory, or RAND.

Although the MPEG-1 standard was developed in 1989, the patent thicket challenges for the MPEG standards were not significantly addressed until after the release of the draft MPEG-2 standard in 1993. Given that the set of patents necessary to practice the MPEG-2 standard would come from a number of firms, the potential problem of double marginalization (Viscusi et al. 2000) had to be addressed in addition to the patent thicket issues,. As a result of the activities of informal meetings in 1992 and 1993 regarding intellectual property matters, a separate MPEG Intellectual Property Rights working group (MPEG IPR) was formed to specifically address issues such as: $(a)$ how to identify which patent holders were willing to participate in this effort; $(b)$ how to know whether they own rights necessary for implementation of MPEG-2 core technology; and $(c)$ how to establish the entity's administrative structure as an ongoing effort that works with new licensees and licensers, the licensing structure, and the allocation of royalties.

Early on, the MPEG-2 community agreed on the need for an innovative way to overcome the underlying patent thicket. Otherwise, the difficulty of gaining access to a large enough body of the necessary MPEG-2 patents would jeopardize the interoperability and implementation of digital video. Since any licensing negotiations were left to the parties concerned and were performed outside of the ITU standard setting process, several of the key companies participating in the MPEG process were concerned that patent rights clearances would be an issue.

Following a series of meetings held in 1993 and 1994, the MPEG IPR working group reached a consensus about the creation and operation of the pool, and a licensing entity called MPEG LA was formed in order to administer the patent pool for virtually all of the patents essential to the MPEG-2 standard. While MPEG LA, did not have a track record of identifying essential patents, it did have a detailed written document that described the requirements for implementing the MPEG-2 standard. The IP Guidelines did not contain a working definition of either essentialness or patent thickets, but MPEG LA developed an objective third-party process that would prove not only the existence of a patent thicket but could also define its boundaries in terms of an objective determination of essentialness.

Another challenge facing MPEG LA was identifying the set of patents to compare against the standard. While those in the MPEG-2 process would have to abide by the RAND licensing policies required by the ITU standards bodies, it was by no means certain that essential patents would be held only by those participating in the standard setting process.

MPEG LA thus commissioned a massive study of the potentially relevant intellectual property throughout the world. While the study involved examining 
more than 8000 US patent abstracts, more than 1000 US patents, and more than 80 US patent prosecution histories, the prospects of getting potential pool members to submit their MPEG-relevant patents for evaluation and potential inclusion involved a certain level of uncertainty. In the laser eye surgery industry, however, the uncertainties were far more daunting.

Beginning in 1984, Dr. Charles Munnerlyn began to design an excimer laser surgical system that could be used to perform clinical surgery on the human eye without the use of scalpels or manually cutting the cornea. He partnered with a company called VISX to develop a system for the new procedure, which they called PRK. PRK showed tremendous promise for correcting nearsightedness and astigmatism. One of the primary obstacles to bringing PRK to market, however, was obtaining FDA approval. Because a PRK device would be a medical device, VISX spent tens of millions of dollars on FDA-mandated clinical trials, starting in 1987, before the FDA granted approval in 1996.

The commercialization of PRK by VISX faced another significant hurdle in the form of intellectual property issues as additional firms were developing laser refractive surgery devices, including Summit Technologies, which owned patents that potentially blocked VISX from implementing a PRK device. According to Josh Newberg, at the time a litigator at the FTC,

With each of the firms vying for capital to finance the long lead time from prototype, through clinical trials, to FDA approval, Summit and VISX had to make educated guesses about the relative scope of each other's patent portfolios based on very limited information. The stakes were huge. If Summit was found to have a blocking position over VISX, it could exclude VISX from the marketplace altogether. ${ }^{7}$

In this instance the blocking situation was mutual, as VISX had patents that blocked Summit from fully implementing a PRK device, and vice versa (Newberg 2000). According to VISX CEO Mark Logan, the underlying patent thicket was suffocating both firms and "neither firm could raise any money without settling the patent issues." 8 While the patent thicket threatened to thwart the development of laser eye surgery altogether, both firms were eager to find a structure that would allow them to proceed with their FDA trials and ultimately bring a PRK device to market.

To solve their patent thicket problem, VISX and Summit formed a patent pool called Pillar Point Partners (P3) on June 3, 1992. Summit contributed 7 patents to the pool, and VISX contributed 18 patents. Collectively, these 25 patents contained more than 500 method and apparatus claims.

Having cleared the patent thicket for PRK for themselves, Summit and VISX returned to the marketplace and then competed vigorously against each other, including during the FDA clinical trial phase. Summit received FDA approval

\footnotetext{
7 Interview with Josh Newberg, March 9, 2004. Professor Newberg left the FTC after the VISX litigation and is now a professor at the University of Maryland.

${ }^{8}$ Interview with Mark Logan, July 1, 2003.
} 
in October of 1995, and VISX received FDA approval 5 months later. In the ensuing months, both firms expanded the PRK market as competitors, but they were soon challenged by the antitrust enforcement regime based on their cooperative effort to clear the PRK patent thicket.

\section{ANTITRUST REVIEW}

Any organization concerned about potential antitrust issues has the right to submit a proposed agreement or structure in advance to antitrust enforcement officials for evaluation. At the DOJ this process is called the Business Review Procedure. ${ }^{9}$ The FTC has a similar procedure for issuing Advisory Opinions. ${ }^{10}$ Preparing a request for ex ante antitrust review is both cumbersome and expensive, and many smaller companies do not submit such requests.

Given the troubled history of patent pools, the management of MPEG LA was justifiably concerned about antitrust scrutiny. Fortunately, however, the proposed MPEG-2 pool would be evaluated under the recently enacted provisions of the IP Guidelines, which explicitly acknowledge that patent pools may provide procompetitive benefits. Having crafted a structure as procompetitive as they thought possible, MPEG LA submitted its request for Business Review on April 28, 1997. ${ }^{11}$ The DOJ issued a Business Review letter on June 26, 1997, stating that it was "not presently inclined to initiate antitrust enforcement action against the conduct" 12 proposed by MPEG LA.

The DOJ began its formal analysis of the proposed patent pool with an inquiry into the validity of the patents and their relationship to each other, stating that attempts to shield invalid or expired intellectual property rights would not withstand antitrust scrutiny. Assuming that all of the patents to be included in the pool were valid, and based on the representations of the complementary nature of those patents, the DOJ acknowledged that a package license for patents in a patent thicket "can be an efficient and pro-competitive method of disseminating those rights to would-be users." ${ }^{13}$ In the case of MPEG, the DOJ indicated that it viewed the pool as a procompetitive aggregation of intellectual property. The DOJ's comfort with that position was enhanced by the fact that MPEG LA had used an independent expert to determine which patents were essential to comply with the MPEG-2 standard, thus objectively defining the boundaries of the underlying patent thicket.

The MPEG pool ultimately became the "gold standard" for patent pool formation, and a number of subsequent patent pools were formed following the

928 C.F.R. $\S 50.6$.

10 16 C.F.R. § 1.1 et sequation

11 Letter from Garrard Beeney to Joel Klein, April 28, 1997.

${ }^{12}$ Letter from Joel Klein, June 26, 1997, available at http://www.gov/atr/public/busreview/1170.htm

13 Id. 
pattern set by MPEG. Each of those pools, however, was based on a standard. The lack of patent pool formation outside of the standards-based context may be due, in part, to the antitrust entanglements of the PRK pool, which did not have the benefit of a standard to demonstrate the existence of an underlying patent thicket.

Unlike MPEG LA, P3 did not submit its structure for antitrust review, and almost exactly two years after VISX received FDA approval to begin selling PRK devices in the United States, the FTC issued a complaint on March 24, 1998, alleging that Summit and VISX had violated the antitrust laws. The FTC's complaint contained several assumptions, however, which were core to its argument. Contrary to the assertions of VISX and Summit, the FTC disputed the existence of an underlying patent thicket. Critical to this position was the FTC's belief that the primary VISX patent was invalid, asserting that it had been obtained fraudulently by withholding relevant information from the PTO during prosecution. The FTC also implicitly assumed that VISX and Summit were no longer competing aggressively because of the existence of the $\mathrm{P} 3$ pool, despite the fact that the two firms were still competing with one another in the sale or lease of PRK equipment.

The FTC sought an order requiring VISX and Summit to dissolve the patent pool and prohibiting the firms from fixing the prices that doctors must pay to use the firms' PRK lasers. Faced with an aggressive and well-funded government agency, neither VISX nor Summit was in a position to put up much of a fight.

VISX and Summit settled with the FTC in August 1998, and agreed to dissolve the pool. The FTC continued to allege that the VISX patent was invalid, but VISX ultimately prevailed in a decision by an administrative law judge in June of 1999. Despite the FTC's initial allegations of fraud before the PTO, VISX was further vindicated when the PTO issued a reexamination certificate reaffirming the validity of the VISX patent in September 2000. The FTC then reopened the case and dismissed the complaint altogether in February 2001.

Could the PRK pool have been formed in such a way so as to survive antitrust scrutiny? Given the erroneous position that the FTC took on the VISX patent, the pool was likely doomed from the start. The approach taken by the FTC, however, is still subject to criticism, as many of the assumptions upon which it based its initial actions were shown to be suspect (Newberg 2000), which raises the question as to whether the FTC action was ultimately in the public interest.

Carl Shapiro (2000) raises two particularly thorny issues regarding patent thickets in analyzing the VISX and Summit result. First, if the two firms reasonably believed that their respective patent portfolios blocked each other at the time they formed the pool, was such a belief sufficient to justify the formation of a pool? How hard were they required to look into the validity of each other's patent claims before agreeing to form the P3 
pool? Second, assuming that each firm believed it could work around the other's patents, would forcing them to do so ultimately benefit the consumer? Shapiro also questions the FTC's insistence that a cross-license was a superior alternative to a patent pool, as any new entrant would have to negotiate two separate licenses in order to access the necessary PRK patents.

When comparing the MPEG and PRK pools, Newberg (2000) suggests that certain differences may have been a function of their respective industries. In examining the MPEG pool, Newberg notes that the pool members are huge firms with enormous resources whose main business is not the licensing of these pooled patents, but rather, the manufacture and sale of telecommunications and consumer electronics hardware.

In contrast, Newberg points out that VISX and Summit were small start-up companies that were trying to create a completely new industry based on a technological innovation. They faced a capital-intensive technology, a long product development cycle, massive regulatory barriers, and potentially ruinous patent infringement litigation. For Summit and VISX, the laser refractive surgery business was the only business, and a single adverse patent ruling - or even the perception of vulnerability to adverse patent rulings - could dry up their capital and put them out of business (Newberg 2000, p. 28).

Newberg also justifies their license fee arrangement, noting that instead of trying to recover their capital investment by charging high machine prices, VISX and Summit presented the marketplace with a substantially lower machine acquisition cost compared to the actual cost of the machine. To make up for the lower revenues from machine sales, Newberg argues that VISX and Summit were justified in using the per-procedure fee as a kind of metering device, "the more the machines were used, the more money Summit and VISX would make in procedure fees" (Newberg 2000, p. 28). Newberg also identifies the benefit of using "the pooling arrangement to reduce the risk of [patent] litigation, while continuing to compete on machine sales, and also as a way of hedging the risk that one firm would receive FDA approval later, or perhaps not at all" (p. 28).

Although neither the DOJ nor the FTC specifically made an assessment of the existence or nonexistence of an underlying patent thicket, the DOJ was able to assume the existence of a thicket based on the procedures put forward by MPEG that were designed to evaluate the essentialness of patents submitted for pool inclusion.

Given the reliance on a standard for the determination of essentialness, the DOJ's assumption was a safe one. In the case of PRK pool, however, the FTC appears to have incorrectly assumed that no thicket existed and proceeded accordingly.

The MPEG and PRK pools were similar in many respects. They were both formed around emerging technologies in order to facilitate adoption of those technologies. They were also both formed around a collection of blocking and 
complementary patents. Ultimately, the MPEG patent pool appears to have survived the antitrust examination for two primary reasons. First, MPEG appears to have specifically crafted their pooling agreements in order to avoid antitrust problems using the IP Guidelines. Second, and certainly equally important, MPEG LA was able to develop an objective process that demonstrated the existence of a thicket coincident with the proposed pool.

\section{NANOPOOLS AS A POSSIBLE SOLUTION TO PATENT THICKETS}

A firm with a nanotechnology patent that finds itself enmeshed in a patent thicket has a number of strategic options. It can sue anyone that it finds that may be potentially infringing its patent, but if it attempts to commercialize its patent, either it or its potential licensees face the same litigation risk from other nanotechnology patent holders. In addition, bringing a patent infringement action in court is expensive. According to the American Intellectual Property Law Association, the median cost for a patent litigation can often exceed $\$ 2$ million and easily reach $\$ 4$ million (AIPLA 2003). Particularly for startup firms, such costs could be prohibitive.

An alternative strategy would be for nanotechnology patent holders to form a patent pool, both clearing the nanothicket for that technology and facilitating "one-stop technology platform licensing" (Horn 2003). Such arrangements avoid the problems of double-marginalization and economic holdup by essential patent holders, and in the case of pools based on standards, have survived antitrust scrutiny.

The American National Standards Institute's Nanotechnology Standards Panel (ANSI-NSP) was established by ANSI in August 2004 in order for the major institutions with a stake in the nanotechnology industry to come together and work toward establishing a set of standards. ${ }^{14}$ The goal of ANSI-NSP is to coordinate the agreement of such standards as nomenclature/terminology with which to communicate, as well as materials properties and measurement procedures to facilitate the commercialization of the variety of uses and applications of nanotechnology. As with the MPEG pool and similar standards-based pools such as IEE-1394 (Firewire) and DVDs, the standards document itself can provide ample guidance as to which patents are essential and thus should be included in the pool.

The standards-setting process for nanotechnology is in its infancy, however, and the prospects for the development of standards remain uncertain. Even if ANSI-NSP can develop some standards, there may be nanothickets for which

14 American National Standards Institute. "About the Nanotechnology Standards Panel." Available at http://www.ansi.org/standards' activities/standards 'boards 'panels/nsp/overview.aspx. Accessed January 8, 2006. 
standards have yet to be developed. In these areas, an alternate strategy would be needed to form a nanopool, but in the absence of a standard, extreme care should be exercised to avoid antitrust entanglements.

Nanothickets are growing, and firms will be forced to develop strategic responses. Whether nanopools are formed using standards or reference models, the nanopooling strategy provides a mechanism for clearing the nanothickets and bringing nanotechnology-based products to the marketplace.

\section{ACKNOWLEDGMENTS}

This research was supported in part by the National Science Foundation under Grant No. IIS 0425116. Research assistance was also provided by Lian Jian and Omer Kareem.

\section{REFERENCES}

AIPLA. 2003. Report of the Economic Survey 2003. American Intellectual Property Law Association. Washington, DC: Fetzer-Kraus, Inc.

BAwA, R. 2004. Nanotechnology patenting in the US. Nanotechnology Law \& Business Journal 1(1), Article 5.

BittLingmayer, G.L. 1988. Property rights, progress, and the Aircraft Patent Agreement. Journal of Law and Economics 31(1), 227-248.

CARLSON, S.C. 1999. Patent pools and the antitrust dilemma. Yale Journal on Regulation $16(2), 359-399$.

CASSADY, R., Jr. 1959. Monopoly in motion picture production and distribution: 19081915. Southern California Law Review 32, 325-390.

Chol, J. 2003. Patent Pools and Cross-Licensing in the Shadow of Patent Litigation. CESinfo Working Paper Series No. 1070. Available at http://ssrn.com.abstract466062 (accessed November 17, 2006).

Clark, J., J. Piccolo, B. Stanton, and K. Tyson 2000. Patent pools: a solution to the problem of access in biotechnology patents? United States Patent and Trademark Office. Available at www.uspto.gov/web/offices/pac/dapp/opla/patentpool.pdf (accessed November 17, 2006).

Clarkson, G. 2004. Objective Identification of Patent Thickets: A Network Analytic Approach. Harvard Business School Doctoral Thesis. Cambridge, MA: Harvard University.

Clarkson, G. 2005. Patent informatics for patent thicket detection: a network analytic approach for measuring the density of patent space. Academy of Management Conference, Honolulu.

Cournot, A.A. 1838. Researches into the Mathematical Principles of the Theory of Wealth. Tr. Nathaniel Bacon (New York: The Macmillan Co. 1897).

DARBY, M.R., and L.G. ZUCKER 2003. Grilichesian breakthroughs: inventions of methods of inventing and firm entry in nanotechnology. NBER Working Paper 9825. (National Bureau of Economic Research), available at http://www.nber.org/papers/w9825 (accessed November 17, 2006). 
ETC. 2005. Nanotech's 'Second Nature' Patents: Implications for the Global South. ETC Group. Available at http://www.etcgroup.org/en/materials/publications. html?id=54 (accessed November 17, 2006).

FreEMAN, L.C. 1979. Centrality in social networks: conceptual clarification. Social Networks 1(1), 215-239.

Fruchterman, T.M.J., and E.M. ReINGOLD 1991. Graph drawing by force-directed placement. Software-Practice \& Experience 21(11), 1129-1164.

FTC. 2002. Patent pools and cross-licensing: when do they promote or harm competition? in FTC Hearings on Competition and Intellectual Property Law and Policy in the Knowledge-Based Economy. Washington, D.C. Federal Trade Commission.

FTC. 2003. To Promote Innovation: The Proper Balance of Competition and Patent Law and Policy. Washington, D.C. Federal Trade Commission.

Gilbert, R.J. 2002. Antitrust for Patent Pools: A Century of Policy Evolution. 2004 Stanford Technology Law Review 3.

Glover, G.J. 2002. Patent thickets and innovation markets reviewed. National Law Journal 24(56), C10.

GRINDLEY, P.C., and D.J. TEECE 1997. Managing intellectual capital: licensing and crosslicensing in semiconductors and electronics. California Management Review $39(2), 8-41$.

Heller, M.A., and R.S. Eisenberg 1998. Can patents deter innovation? The anticommons in biomedical research. Science 280(5364), 698-701.

HoRn, L. 2003. Alternative approaches to IP management: one-stop technology platform licensing. Journal Of Commercial Biotechnology 9(2), 119-127.

Lemley, M.A. 2005. Patenting nanotechnology. Stanford Law Review 58, 601.

Lerner, J., and J. Tirole 2004. Efficient patent pools.NBER. American Economic Review 94(3), 691-711.

Lerner, J., M. StrojwAs, and J. TiRole 2003. Cooperative Marketing Agreements Between Competitors: Evidence from Patent Pools. Working Paper 9680 (National Bureau of Economic Research), available at http://www.nber.org/papers/w9680 (accessed November 17, 2006).

Lux. 2003. The Nanotech Report 2003. Lux Research Inc. New York.

Lux. 2005. The Nanotech Intellectual Property Landscape. Lux Research Inc. New York.

MARSDEN, P.V. 1990. Network data and measurement. Annual Review of Sociology 16, 435-463.

Merges, R.P. 1996. Contracting into liability rules: intellectual property rights and collective rights organizations. California Law Review 84(5), 1293.

Merges, R.P. 1999. Institutions for Intellectual Property Transactions: The Case of Patent Pools. Berkeley: University of California at Berkeley.

MolendA, J.J. 2004. The importance of defining novel terms in patenting nanotechnology inventions. Nanotechnology Law \& Business Journal 1(1), Article 8.

Mouttet, B. 2005. Nanotech and the U.S. patent \& trademark office: the birth of a patent class. Nanotechnology Law \& Business Journal 2(3), Article 5.

NewBerg, J.A. 2000. Antitrust, patent pools, and the management of uncertainty. Atlantic Law Journal 3, 1-30.

Newman, M.E.J. 2000. Who is the best connected scientist? A study of scientific coauthorship networks. Pp. 337-370 in E. Ben-Naim, H. Frauenfelder and Z. Toroczkai (eds.), Complex Networks. Berlin: Springer. 
Newman, M.E.J. 2001. The structure of scientific collaboration networks. Proceedings of the National Academy of Sciences of the United States of America 98, 404-409.

Podolny, J.M., and T.E. STUART 1995. A role-based ecology of technological change. American Journal of Sociology 100(5), 1224-1260.

Podolny, J.M., T.E. StuART, and M.T. HANnAN 1996. Networks, knowledge, and niches: competition in the worldwide semiconductor industry, 1984-1991. American Journal of Sociology 102(3), 659-689.

PRICE, D.d.S. 1965. Networks of scientific papers. Science 149(3683), 510-515.

PrICE, D.d.S. 1976. A general theory of bibliometric and other cumulative advantage processes. Journal of the American Society for Information Science 27, 292-306.

PrIEST, G.L. 1977. Cartels and patent licensing arrangements. Journal of Law and Economics 20, 309-377.

REDNER, S. 1998. How popular is your paper? An empirical study of the citation distribution. European Physical Journal B, 4(2), 131-134

SAMPAT, B. 2004. Examining patent examination: an analysis of examiner and applicant generated prior art. National Bureau of Economics, 2004 Summer Institute, Cambridge, MA.

SCHROEDER, M. 1999. Using singular value decomposition to visualise relations within multi-agent systems. Pp. 313-318 in Third Annual International Conference on Autonomous Agents. Seattle: ACM Press.

SHAPIRO, C. 2000. Navigating the patent thicket: cross licenses, patent pools, and standard-setting. Innovation Policy and the Economy 1, 119-150.

SHAPIRO, C. 2003. Antitrust limits to patent settlements. Rand Journal of Economics 34(2), 291-411.

Stuart, T.E., and J.M. Podolny 1996. Local search and the evolution of technological capabilities. Strategic Management Journal 17(Special Issue: Evolutionary Perspectives on Strategy), 21-38.

TAYLOR, D.S. 1992. The sinking of the United States electronics industry within Japanese patent pools. George Washington Journal of International Law and Economics 26, 181-212.

TEECE, D.J. 1998. Capturing value from knowledge assets: the new economy, markets for know-how, and intangible assets. California Management Review 40(3), 5579.

TeECE, D.J. 2000. Managing Intellectual Capital. Oxford: Oxford University Press.

THOMSON, R. 1987. Learning by selling and invention: the case of the sewing machine. The Journal of Economic History 47(2), 433-445.

Vaughan, F.L. 1925. Patent pools. Pp. 34-68 in Economics of our Patent System. New York: The Macmillan Company.

Viscusi, W.K., J.M. VERnON, and J.E. HARRINGTON 2000. Economics of Regulation And Antitrust, 3rd ed. Cambridge, MA: MIT Press.

Wasserman, S., and K. Faust 1994. Social Network Analysis Methods And Applications. New York: Cambridge University Press.

ZuCKER, L.G., and M.R. DARBY 2005. Socio-economic impact of nanoscale research: initial results and nanobank. NBER Working Paper No. 11181. 